\title{
Numerical simulation of an intense precipitation event over Rudraprayag in the central Himalayas during 13-14 September 2012
}

\author{
A Chevuturi ${ }^{1}$, A P Dimri ${ }^{1, *}, \mathrm{~S} \mathrm{Das}^{2}, \mathrm{~A} \mathrm{Kumar}^{3,4}$ and D Niyogi ${ }^{4}$ \\ ${ }^{1}$ School of Environmental Sciences, Jawaharlal Nehru University, New Delhi, India. \\ ${ }^{2}$ India Meteorological Department, New Delhi, India. \\ ${ }^{3}$ Earth System Science Interdisciplinary Center, University of Maryland, College Park, MD, USA. \\ ${ }^{4}$ Purdue University, West Lafayette, Indiana, USA. \\ *Corresponding author.e-mail: apdimri@hotmail.com
}

A recent heavy precipitation event on 13 September 2012 and the associated landslide on 14 September 2012 is one of the most severe calamities that occurred over the Rudraprayag region in Uttarakhand, India. This heavy precipitation event is also emblematic of the natural hazards occuring in the Himalayan region. Study objectives are to present dynamical fields associated with this event, and understand the processes related to the severe storm event, using the Weather Research and Forecasting (WRF ver 3.4) model. A triple-nested WRF model is configured over the Uttarakhand region centered over Ukhimath $\left(30^{\circ} 30^{\prime} \mathrm{N} ; 79^{\circ} 15^{\prime} \mathrm{E}\right)$, where the heavy precipitation event is reported. Model simulation of the intense storm on 13 September 2012 is with parameterized and then with explicit convection are examined for the $3 \mathrm{~km}$ grid spacing domain. The event was better simulated without the consideration of convection parameterization for the innermost domain. The role of steep orography forcings is notable in rapid dynamical lifting as revealed by the positive vorticity and high reflectivity values and the intensification of the monsoonal storm. Incursion of moist air, in the lower levels, converges at the foothills of the mountains and rise along the orography to form the updraft zone of the storm. Such rapid unstable ascent leads to deep convection and increases the condensation rate of the water vapour forming clouds at a swift rate. This culminates into high intensity precipitation which leads to high amount of surface runoff over regions of susceptible geomorphology causing the landslide. Even for this intense and potentially unsual rainfall event, the processes involved appear to be the 'classic' enhanced convective activity by orographic lifting of the moist air, as an important driver of the event.

\section{Introduction}

Intense precipitation events over the mountainous region like the Himalayas can lead to secondary events like flashfloods and landslides (Wooley 1946; Das et al. 2006). Such an event can cause landslides, property damage, injuries, and even fatalities. High impact weather events are frequently noted over the regions with heterogeneous topography like the Himalayas during summer monsoon, when atmospheric flow interacts with orography (Barros et al. 2006). Orography of the Himalayan region enhances the process leading to convective lifting that produces high intensity precipitation (Kumar et al. 2012, 2014). An extreme precipitation event, sometimes referred to

Keywords. WRF; convective systems; orographic precipitation; explicit physics; Himalayas. 
as a 'cloudburst', is a weather phenomenon featuring a sudden high rate of precipitation over a localized region (AMS 2005). It is generally characterized by a high rate of rainfall of the order $100 \mathrm{~mm}$ per hour and affects a small region up to $20-30 \mathrm{~km}^{2}$ for short amount of time (Das et al. 2006; Ashrit 2010; IMD 2010). Such extreme weather events are usually associated with strong winds and lightning along with formation of convective clouds. Cumulonimbus convection is seen with moist thermodynamic instability and deep, rapid dynamical lifting due to steep topography (Wooley 1946; Das et al. 2006; Ashrit 2010; IMD 2010). Even without the high intensity precipitation event being classified as an extreme cloudburst event, the hydrology or geomorphology of the Himalayan region is prone to flashfloods and landslides with the rainfall amounts that would be considered moderate in the plains (Das et al. 2006). As this definition of cloudburst is a colloquial criterion of delimiting a cloudburst from other high intensity precipitation events, the paper will use the terms such as intense, heavy or extreme precipitating events.

There has been interest to study extreme precipitation in the Himalayan region to better understand the various processes associated with them. Majority of the recent studies have been in response to the devastating 'Leh Cloudburst' event in 2010 (Ashrit 2010). Kumar et al. (2012) analyzed the Leh event and showed that the choice of microphysics scheme impacted the simulation. Rasmussen and Houze (2012) and Kumar et al. (2014) studied the detailed mesoscale convective system occurring during the Leh flashfloods using observational data and models such as the Weather Research and Forecasting (WRF) and Land Information System. Thayyen et al. (2013) studied the cloudburst event and the associated flashfloods using atmospheric modelling and hydrological analysis and adopted a reverse algorithm to obtain the rainfall estimates using the flood measurement. Similarly, Hobley et al. (2012) used geophysical changes that occurred during the Leh cloudburst event to reconstruct the precipitation pattern during the storm.

The focus of this study is the model analysis of a heavy precipitation event that occurred over the district of Rudraprayag in Uttarakhand, India (study domain). The event affected villages in the Ukhimath (or sometimes known as Okhimath) Tehsil of the Rudraprayag district. Figure 1(a) shows the daily precipitation for the month of September 2012 (DMMC 2012). The event took place around 13 September 20121930 UTC (14 September 20120100 IST); that is on the nigh t of 13 September 2012 (Sphere India 2012). High intensity precipitation was recorded in the region which triggered a landslide and debris flow in the early hours of 14 September 2012. The event was associated with fatalities and damage to infrastructure and property, with reports of up to 34 villages being impacted (DMMC 2012). Figure 1(b) shows the Doppler Weather Radar (DWR) based reflectivity observed over the region valid for 13 September 20121930 UTC (14 September 201201 IST). The convective activity associated with the Rudraprayag precipitation event is noted in the reflectivity fields as a localized storm cell (demarcated by a red oval). Figure 1(cd) is the image of the Meteosat-5 satellite infrared brightness temperature, which depicts cloud cover and storm development over the study domain. The storm intensity peaks around 13 September 201218 UTC and intensity reduced after 13 September 201222 UTC. Low values of brightness temperature over the Rudraprayag region are indicative of presence of high cloud tops and convective activity over the study region. This event was reported as a 'cloudburst' in the popular media (e.g., Economic Times 2012), even though it does not exactly fit the typical criteria and is more accurately an intense precipitation event. The region around Rudraprayag is a disasterprone region due to its geotectonic configuration and weather conditions, with frequent occurrences of disasters like earthquakes, thunderstorms, flashfloods, and landslides. Even under this background, this event is considered as one of the biggest disasters in terms of number of lives lost since the formation of the state in 2000 (DMMC 2012).

The Himalayan region is prone to high intensity precipitation (Dimri et al. 2015). There are also secondary impacts associated with heavy precipitation over Himalayan terrain. There is a need to better understand such events in greater detail to mitigate the severe impacts of such commonly occurring meteorological disasters. The region, however, has a sparse observational network and analysing such events continues to be a challenge. Thus, the goal of this paper is to utilize numerical weather prediction for simulation of such weather events over this region. Due to the steep variation in orography of the region, specific emphasis is on identifying various atmospheric triggers initiating convection in relation to the orographic forcings of the Himalayan terrain taking this event as an example.

Considering the results from prior modelling studies to simulate high intensity precipitating events, there is a need to consider the variable orography of the Himalayan region (Leung and Ghan 1995; Dimri et al. 2015). With this consideration, higher resolution (finer grid spacing) simulation is expected to provide a clearer idea of the localized meteorological processes. For grid spacings below 

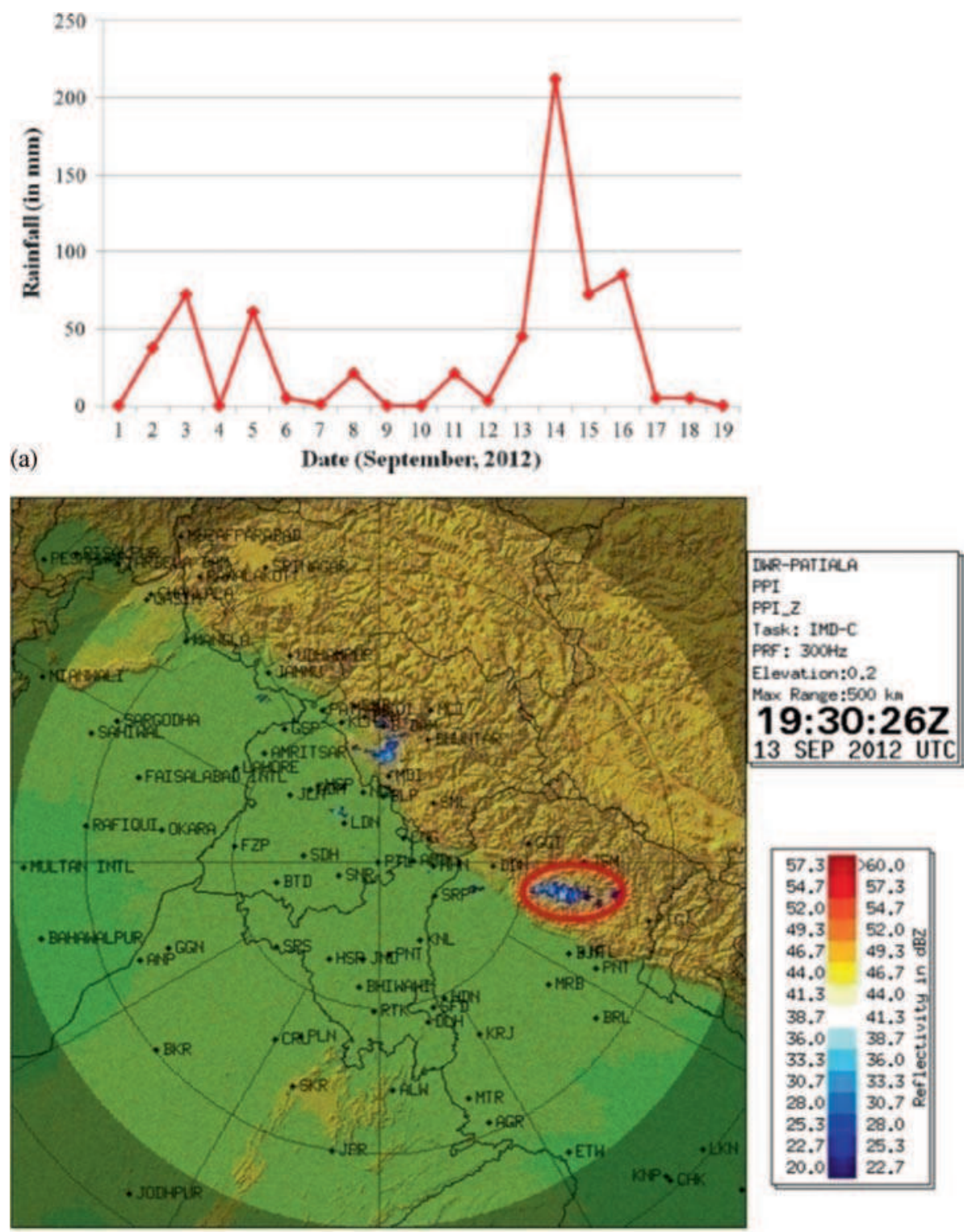

(b)

Figure 1. (a) Daily rainfall ( $\mathrm{mm}$ ) for 1-20 September 2012 at Ukhimath (location reported for the intense precipitation event) (source: DMMC 2012), (b) Observed reflectivity from the IMD Patiala Radar for 13 September 2012 , 1930 UTC (source: IMD Radar output archived at http.//ddgmui.imd.gov.in/storm2012/) with Ukhimath region marked by red circle, (c) Meteosat-5 IR-Tb (brightness temperature) for 13 September 201218 UTC, and (d) same as (c) but for 13 September 201222 UTC.

$10 \mathrm{~km}$, the convection is typically resolved explicitly by grid-scale processes. This is because, the parameterization statistically calculates convection intensity instead of sub-grid level cloud, but as the resolution becomes finer the clouds attain grid scale level (Arakawa 2004). The $10 \mathrm{~km}$ grid spacing threshold has been a subject of investigation (e.g., Deng and Stauffer 2006; Prasad et al. 2014) and convection has resolved explicitly for high resolutions. Gomes and Chou (2010), for instance, state that for horizontal grid spacing smaller than $3 \mathrm{~km}$, the precipitation is dependent on the cloud microphysics scheme. Review of various experiments on the subject in literature suggests that parameterization shows errors in grid spacings between 3 and $25 \mathrm{~km}$, and hybrid methods must be applied for resolving convection (Molinari and Dudek 1992). Weisman et al. (1997) and Done et al. (2004) show that $4 \mathrm{~km}$ resolution with explicit physics is sufficient in mesoscale models to predict processes within a convective system. In simulation with explicitly resolved convection, no sub-grid scale convection is accounted for and fails when there is a lack of grid-scale forcing or intense convective instability (Molinari and Dudek 1992). Over Himalayan region explicit representation of 

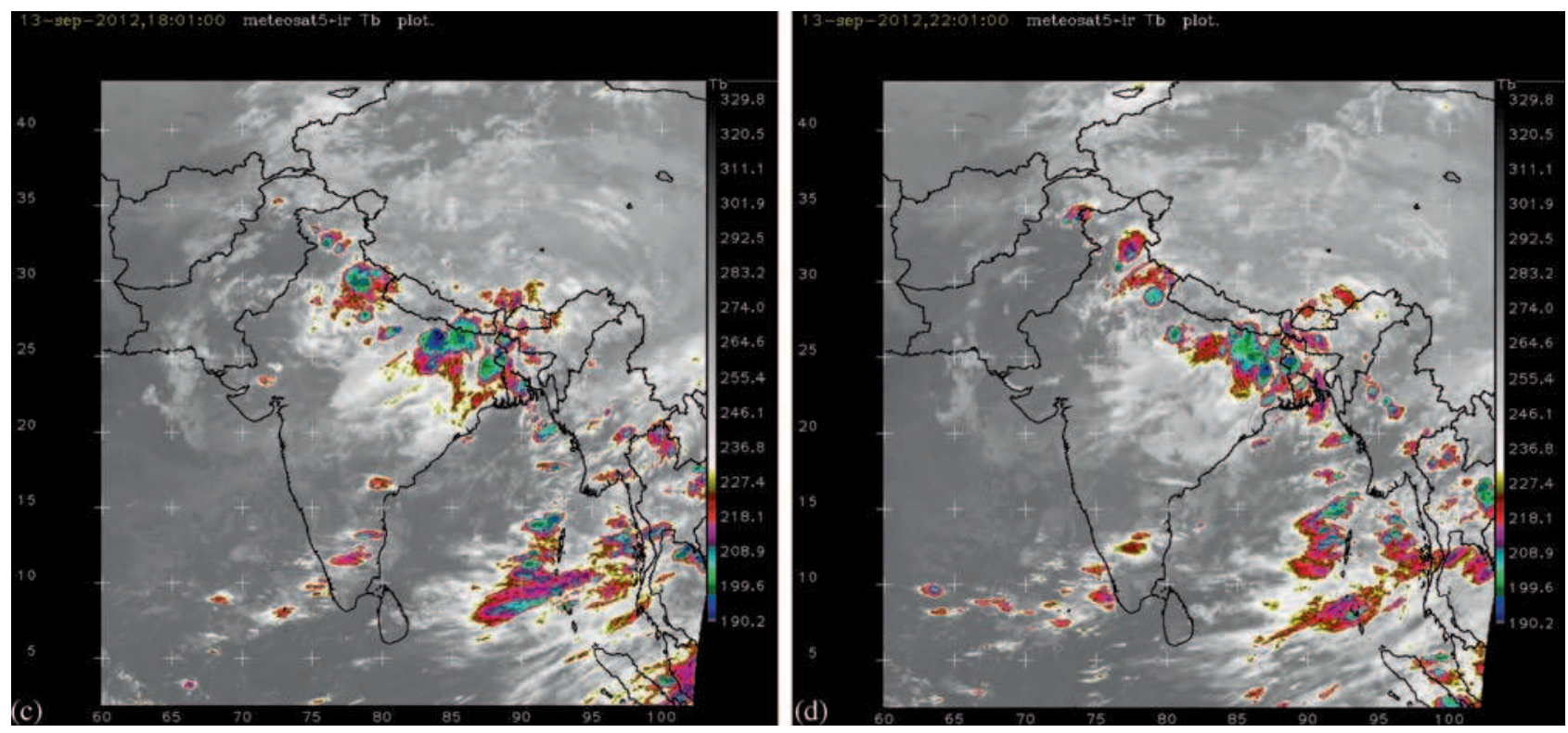

Figure 1. (Continued.)

convection in model simulations is still relatively under studied.

Accordingly, study objective is to simulate a high intensity rain event to understand the various dynamical characteristics associated with the intense precipitation event using the WRF model, with an aim to comprehend the storm development. The study also aims to explain the sensitivity of model for cumulus parameterization at higher resolutions in regions of complex topography.

\section{Data and methodology}

In this study, the WRF model (version 3.4.1) with the Advanced Research WRF (ARW) dynamic solver is used to simulate the event. The WRF model is a mesoscale dynamical model, developed by a multi-institutional collaboration (Wang et al. 2010) including the National Oceanic and Atmospheric Administration (NOAA), USA, the National Center for Atmospheric Research (NCAR), USA, and the academia. The ARW dynamic solver (Skamarock et al. 2008) uses fully compressible non-hydrostatic Euler equations with a hydrostatic option and allows for multiple nesting (Kumar et al. 2008). The model domain is set up over the Uttarakhand region centered over Ukhimath $\left(30^{\circ} 30^{\prime} \mathrm{N} ; 79^{\circ} 15^{\prime} \mathrm{E}\right)$, where the high intensity precipitation was reported. Three nested domains with 27, 9, and $3 \mathrm{~km}$ grid spacing are configured. Figure 2 shows the extent of these domains with the topography of the third domain with $3 \mathrm{~km}$ resolution shown in detail. Model simulations are analyzed for $72 \mathrm{hrs}$ starting with 11 September
201200 UTC. The model performance in simulating the precipitation event is evaluated, along with the large scale atmospheric processes leading to the weather event. The model is run using NCEP final analysis data (FNL), at $1^{\circ} \times 1^{\circ}$ spatial resolution as the initial and lateral boundary conditions. Due to the coarser resolution of the FNL dataset a 12-hour spin-up period has been incorporated before starting the model integration (Skamarock 2004), thus initializing the model at 10 September 201212 UTC. Tropical Rainfall Measuring Mission (TRMM) multi-satellite daily precipitation analysis (TMPA 3B42 V7, Huffman et al. 2007 ) at $0.25^{\circ} \times 0.25^{\circ}$ spatial resolution is used for comparing with the model precipitation fields.

The model equations in ARW are solved with time-split integration using a second-order RungeKutta scheme on the Arakawa C-grid (table 1). The surface layer parameterizations used in the model are based on Noah land surface model scheme and MM5 similarity scheme. The Rapid Radiative Transfer Model (RRTM) is used for longwave radiation parameterization and the Dudhia scheme is used as the shortwave parameterization scheme. WRF single moment six class cloud microphysics scheme and the Yonsei University Scheme (YSU) are used as the planetary boundary layer physics. This model configuration builds on previous work done on the Leh cloudburst by Ashrit (2010), Kumar et al. (2012), and Thayyen et al. (2013). With this configuration, two experiments were conducted with and without explicit cumulus convection for the innermost domain. The Kain-Fritsch cumulus scheme (Kain 2004) was used for convection (hereafter refered as parameterized physics simulation). 


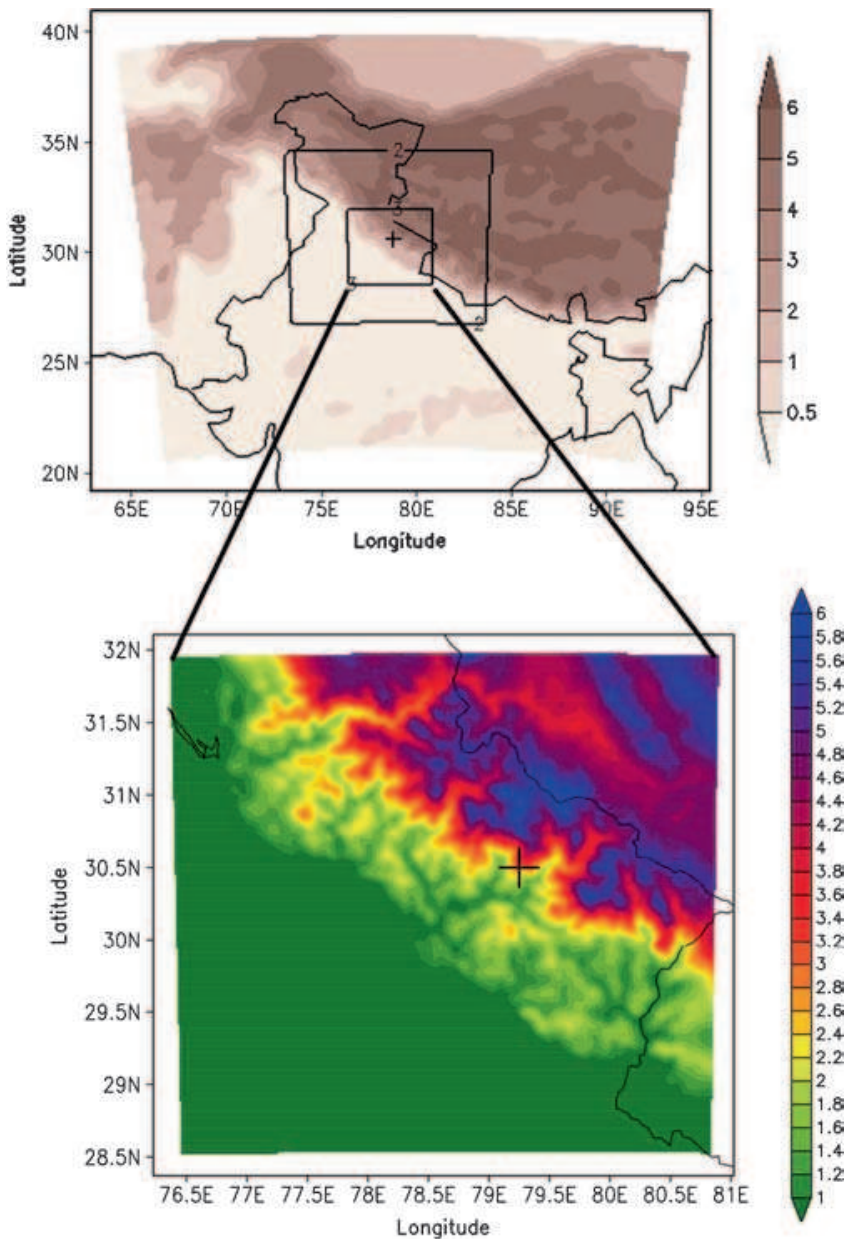

Figure 2. Model domain and topography $\left(\times 10^{3} \mathrm{~m}\right.$; shaded $)$. Shaded region corresponds to model domain 1 ( $27 \mathrm{~km}$ horizontal grid spacing), and fan-shaped boxes with black lines indicate model domain 2 (9 km horizontal grid spacing), and domain 3 (3 km horizontal grid spacing) as marked in the box itself. Detailed topography $\left(\times 10^{3} \mathrm{~m}\right.$; shaded $)$ of domain 3 is shown below. Plus sign indicates location of Ukhimath.

As the intense precipitation was the focus of this event, precipitation verification analysis is conducted. For the verification analysis, a subregion has been demarcated around Ukhimath (between $28.5^{\circ}-31.5^{\circ} \mathrm{N} ; 76.5^{\circ}-80.5^{\circ} \mathrm{E}$ ). Root mean square error (RMSE) is used for precipitation verification, and comparison between the two different model simulation (explicit physics simulation and the parameterized physics simulation) for the domain with $3 \mathrm{~km}$ model resolution (domain 3 ) is analyzed.

Initially, this study was performed using WRF model (version 3.0), but as per Sun and Barros (2013), an error associated with YSU planetary boundary scheme and WRF model mandated redoing the assessment with an updated model. As a result, changes were made to the experimental design and event was simulated using WRF model (version 3.4.1). A brief discussion about the improvements over the previous simulation has also been incorporated in the results and discussion section.

\section{Results and discussion}

\subsection{Comparison with observations}

Analysis of the daily precipitation output shows that high intensity precipitation occurred on 14 September 2012. This is noted in both the model simulations with explicit physics as well as the corresponding daily merged TRMM dataset. Model simulated 6 hourly accumulated precipitation for 13 September 201218 UTC for the $3 \mathrm{~km}$ resolution and the corresponding TRMM observations are shown in figure 3 . Comparing the 6 hourly precipitation patterns, peak rainfall intensity is captured over the Ukhimath region between 13 September 201218 UTC and 14 September 201200 UTC by the model with explicit physics simulation as well as TRMM dataset. The TRMM 3B42 V7 dataset also indicates a relative error of $8.6 \mathrm{~mm} / \mathrm{hr}$ over

Table 1. Details of model configuration and experimental design.

\begin{tabular}{ll}
\hline Model & \multicolumn{1}{c}{ WRF version 3.4 .1} \\
\hline Map projection & Lambert conformal \\
Central point of domain & $30^{\circ} 30^{\prime} \mathrm{N} ; 79^{\circ} 15^{\prime} \mathrm{E}$ \\
Horizontal resolution & Triple nest: 27,9 and $3 \mathrm{~km}$ \\
Horizontal grid scheme & Arakawa C-grid \\
Time integration scheme & Time-split integration using 2nd-order Runge-Kutta scheme \\
Time step & $108 \mathrm{~s}$ \\
Land surface model & Noah land surface model \\
Surface layer model & MM5 similarity model \\
Radiation scheme & Shortwave-Dudhia scheme; Longwave - RRTM \\
Microphysics & WRF single moment 6 class (Hong and Lim 2006) \\
Planetary boundary layer & Yonsei University scheme (Hong et al. 2006) \\
Cumulus parametrization & A. Explicit physics \\
& B. Parameterized physics (Kain-Fritsch scheme) (Kain 2004)
\end{tabular}




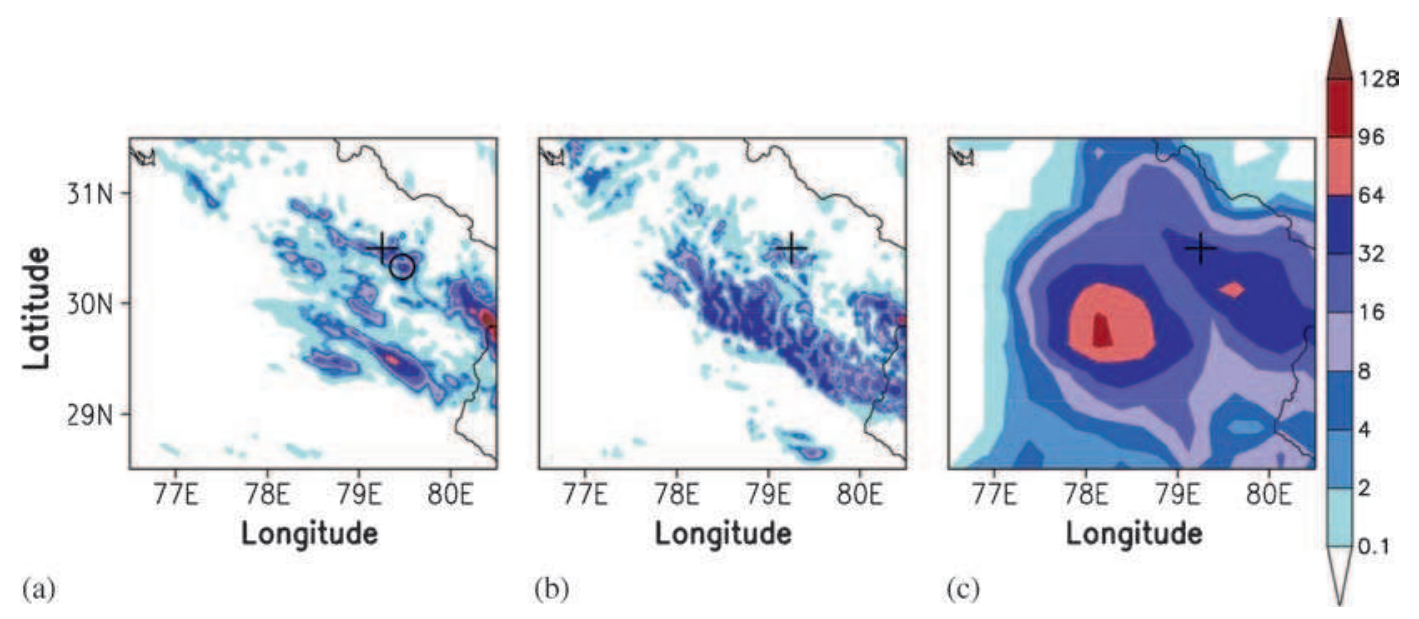

Figure 3. Six-hr accumulated precipitation (mm) for 13 September 201218 UTC for model-simulated domain 3 with (a) explicit physics, (b) parameterized physics, and (c) TRMM observational analysis. Plus sign indicates location of Ukhimath. Black circle indicates the location of precipitation maxima (at $30^{\circ} 19^{\prime} 49^{\prime \prime} \mathrm{N} ; 79^{\circ} 28^{\prime} 09^{\prime \prime} \mathrm{E}$ ).

Ukhimath at 13 September 201218 UTC. The relative error for the TRMM 3B42 V7 is the random fluctuations of the precipitation value from the true precipitation value and calculated according to Huffman (1997).

The precipitation peak is displaced southeast of Ukhimath in the model simulation with explicit physics and is comparable to TRMM observations. This location of peak precipitation (at $30^{\circ} 19^{\prime} 49^{\prime \prime} \mathrm{N}$; $79^{\circ} 28^{\prime} 09^{\prime \prime} \mathrm{E}$ ) is marked in figure $3(\mathrm{a})$ with a circle. Additional analysis of the event is performed at this location. With the spatial extent of the event fixed at the location of precipitation peak, the temporal extent of the precipitation event is analyzed in the model simulation with explicit physics (figure 4). For clarity, the precipitation intensity is analyzed at the precipitation maxima grid point and eight adjacent grid points for both model simulations. Heavy precipitation is simulated at 13 September 201218 UTC with values exceeding $75 \mathrm{~mm}$. In the same figure, it can be seen that the model simulated low intensity precipitation for earlier time periods as well. This indicates formation of small but multiple storm cells over the region. A notable exception is seen in this pattern for model simulation with parameterized physics, showing consistent low values of precipitation on both 13 and 14 September 2012. The explicit physics simulation capture the precipitation pattern as seen in the station data (figure 1a), the intensity of rainfall is not reproduced but is comparable to TRMM estimates of $70 \mathrm{~mm}$. The parameterized physics simulation is not able to capture the precipitation maxima over the Ukhimath region. This difference illustrates that explicitly resolving convection at finer resolutions simulates the storm conditions better than when the convection is parameterized. The peak precipitation amount is captured better by the finer model resolution (domain 3) than the coarser resolutions (domain 1 and 2; figures not shown). Under-representation of station observation or resolution difference between model simulation and observation analysis can be the cause of the variation in the magnitude of precipitation. The enhanced impact of orography on precipitation is seen clearly in finer grid spacing due to better representation of topography. The low density of observation stations cannot capture the maxima spatially or variable patterns of convective precipitation over this region of variable orography due to under-representation of subgrid features in coarser resolutions (Dimri and Niyogi 2013). Exact location of precipitation maxima is elusive even in the observations and needs further investigations.

For a comparative analysis between the two model simulations, RMSE values are shown in table 2. These show different time step of RMSE calculated as a spatial average from the bias (model minus observation from TRMM 3B42 V7) at each grid point. Due to the elusive location of the precipitation maxima, the study area described in the methodology is considered for calculation of the RMSE. From the table, we can observe that the explicit physics simulation typically shows lower RMSE values than the parameterized physics simulations. Only in one case marked with shaded cells in the table does the parameterized physics simulation show lower values of RMSE. Overall explicit physics simulations show lowest RMSE values with TRMM dataset in domain 3 (3 km grid spacing) of the model simulation. The differences between parameterized physics and explicit physics 


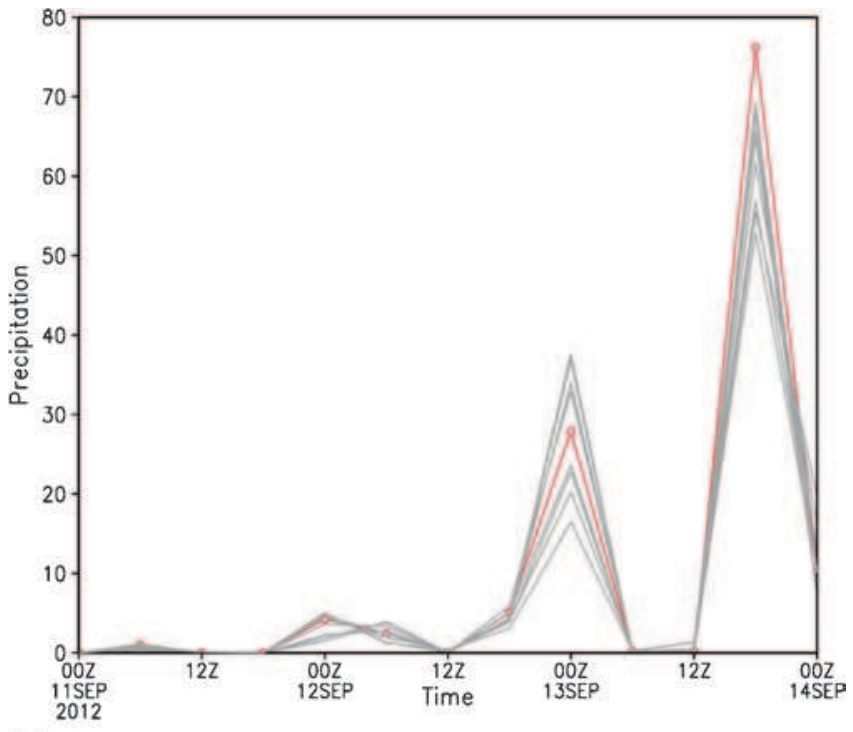

(a)

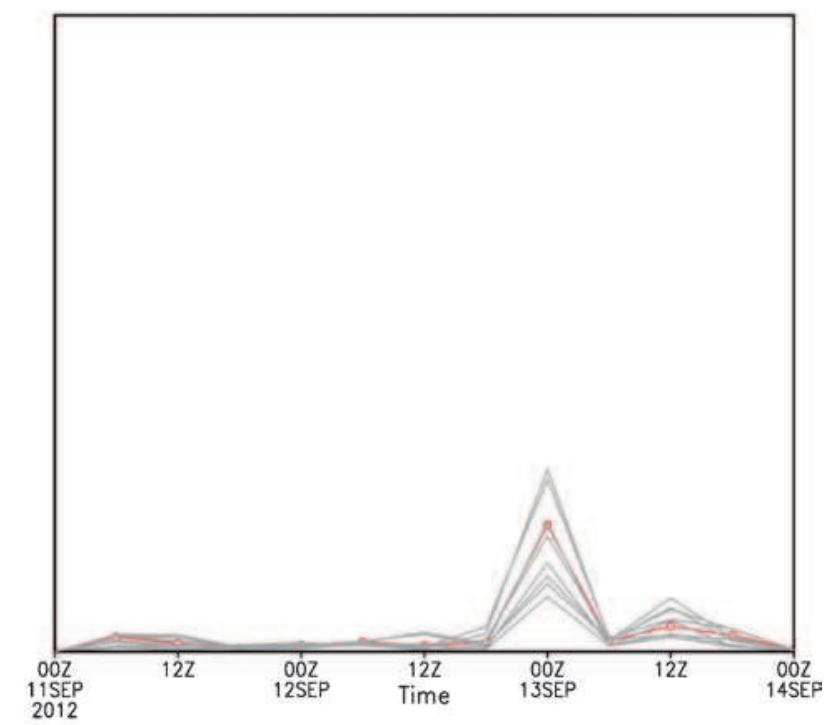

(b)

Figure 4. Time series of 6-hr accumulated precipitation $(\mathrm{mm})$ at location of precipitation maxima at $30^{\circ} 19^{\prime} 49^{\prime \prime} \mathrm{N}$ and $79^{\circ} 28^{\prime} 09^{\prime \prime} \mathrm{E}$ (red line) and eight grid points surrounding it (grey lines) for model-simulated domain 3 with (a) explicit physics and (b) parameterized physics.

simulations are discussed further in detail in the following section.

According to the TRMM analysis, the rainfall maxima occurred around 13 September 201218 UTC. The corresponding time of 'cloudburst' or more specifically the time of the intense precipitating event was reported around 13 September 2012 1930 UTC, which is the night of 13 September 2012 by local reports (DMMC 2012; Sphere-India 2012). This reported time of the event matches well with the model simulation using explicit convection. The storm's maximum intensity was observed around 13 September 20121930 UTC as per the DWR data as reported by the IMD. This is also corroborated

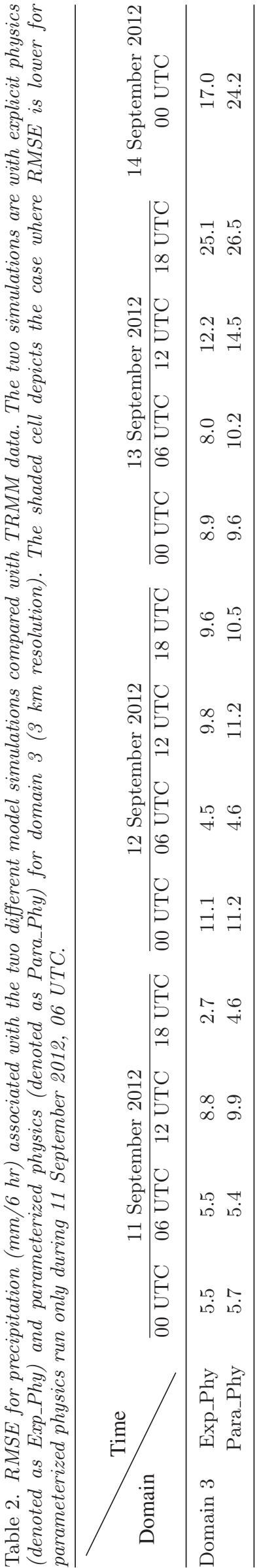


from the information available from Meteosat-5 IR-Tb data shown in figure $1(\mathrm{c}-\mathrm{d})$; where it is seen that the storm intensification is observed on 13 September 201218 UTC and the intensity reduces after 22 UTC. Romatschke and Houze (2010, 2011) and Barros et al. (2004) have also reported occurrence of such small but strong precipitating convective systems over the western Himalayan region which have a diurnal cycle with peaks in night and afternoons.

\subsection{Analysis of the atmospheric processes}

As discussed in the above section, the precipitation maxima is observed at 13 September 2012 18 UTC. In this section, the various atmospheric processes associated with the weather event are discussed with an emphasis on the period around 13 September 201218 UTC.

Large-scale synoptic flow at $850 \mathrm{hPa}$ is shown in figure 5(a), along with the corresponding geopotential height for outer domain with $27 \mathrm{~km}$ grid spacing. Due to the complex topography, the model does not simulate variables over the Ukhimath region. The $850 \mathrm{mb}$ fields are discussed to elaborate on the lower level monsoonal flow during this time period. The figure depicts low pressure belt over the Indo-Gangetic plains. This zone corresponds to the monsoon trough zone that was established over India. This monsoon trough with the well marked low has been reported over the same region by IMD (2012). Indian summer monsoon is associated with large scale convection over the Indian region and precipitation along the monsoon trough zone. Figure 5(b) depicts the flow at $700 \mathrm{hPa}$, showing a clear low pressure zone over the Ukhimath region. This low pressure zone develops strong wind flow along the Himalayas. The flow is southeasterly along the fringe in the Rudraprayag region. The spatial distribution of vertically integrated moisture flux (transport) and divergence fields from the $27 \mathrm{~km}$ domain are shown in figure 5(c). There is notable moisture convergence over southeast of Ukhimath, in the form of small cells. In the simulation, this cellular spatial distribution of the moisture convergence zone is clearly seen. The convergence peak and spatial distribution is similar to the corresponding precipitation maxima and distribution. The moisture convergence zone is concentrated at the windward side of the Himalayan slope and the moisture influx is from the Indo-Gangetic belt towards the Himalayas. The larger flow brings in moisture from the Arabian Sea to this region and potentially causes the convective storm to intensify (figure 5a). This intensification and instability over region is attributed to the buoyancy fields generated due to the moisture incursion and the cloud formation.
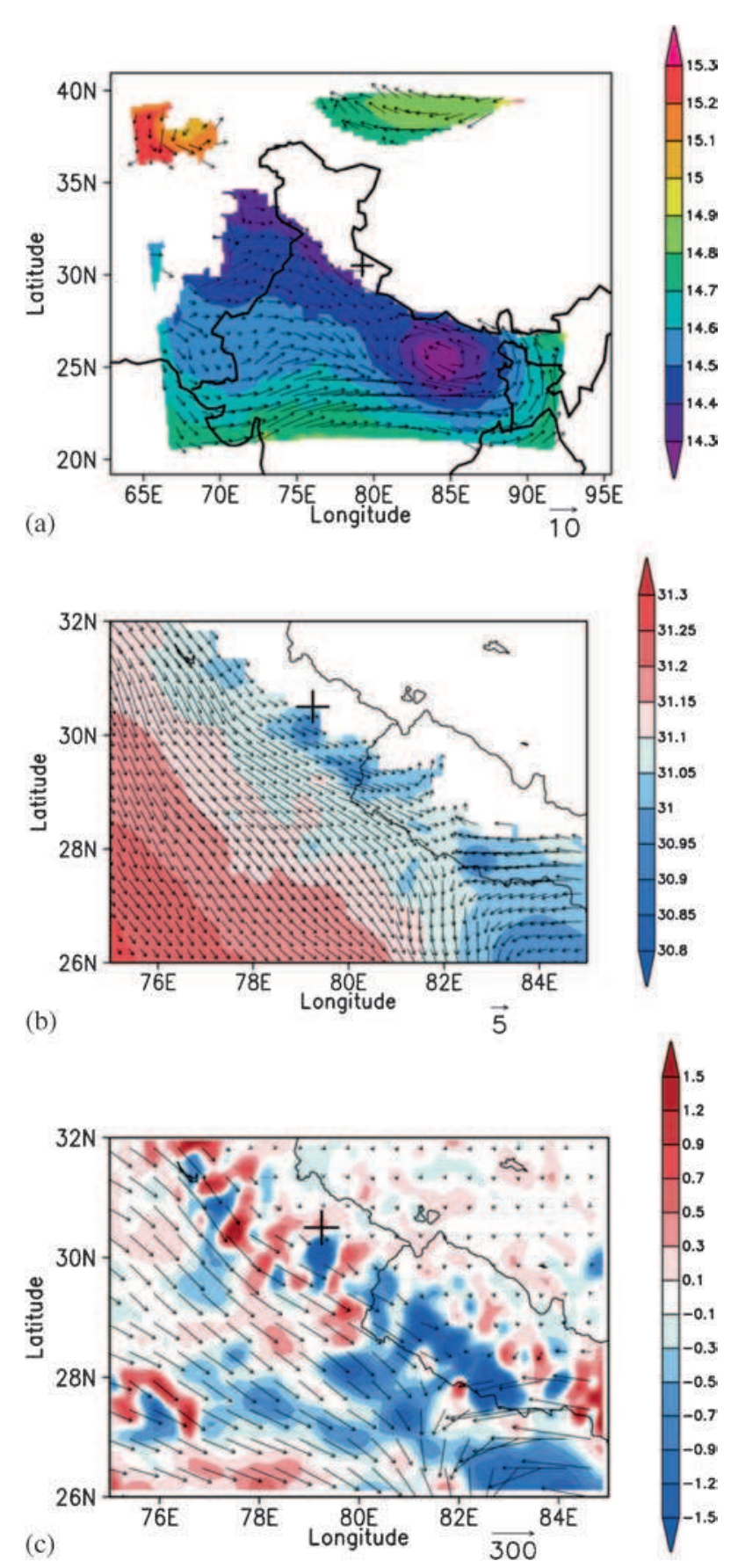

Figure 5. (a) Wind circulation ( $\mathrm{m} \mathrm{s}^{-1}$; vector) at $850 \mathrm{hPa}$ and geopotential height $\left(\times 10^{-2} \mathrm{~m}\right.$; shaded $)$ at $27 \mathrm{~km}$ grid spacing for 13 September $201218 \mathrm{UTC}$, (b) same as (a) but at $700 \mathrm{hPa}$, and (c) same as (b) but with vertical integrated moisture transport $\left(\mathrm{kg} \mathrm{m}^{-1} \mathrm{~s}^{-1}\right.$; vector $)$ and flux $\left(\times 10^{-3}\right.$ $\mathrm{mm}$; shaded). Plus sign indicates location of Ukhimath.

Upper level circulation at $200 \mathrm{hPa}$ for 13 September 201218 UTC for the $3 \mathrm{~km}$ grid spacing with explicit convection (figure 6a) and parameterized physics simulation (figure $6 \mathrm{~b}$ ) is reviewed next. The corresponding outgoing longwave radiation (OLR) fields which depict the cloud formation during this event are shown in figure $6(\mathrm{c}-\mathrm{d})$. The presence of high clouds with colder cloud top temperatures 


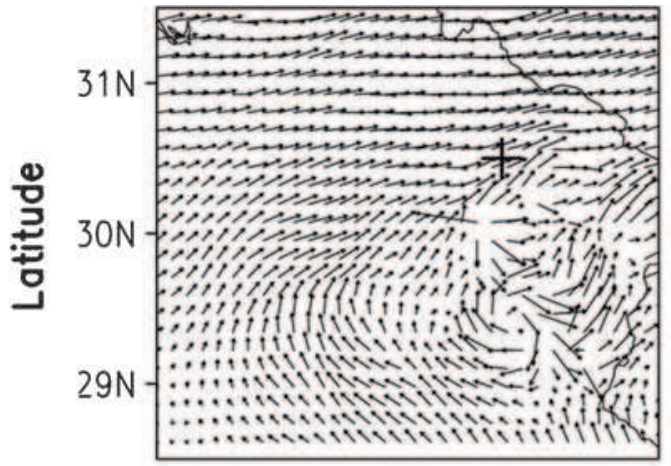

(a)

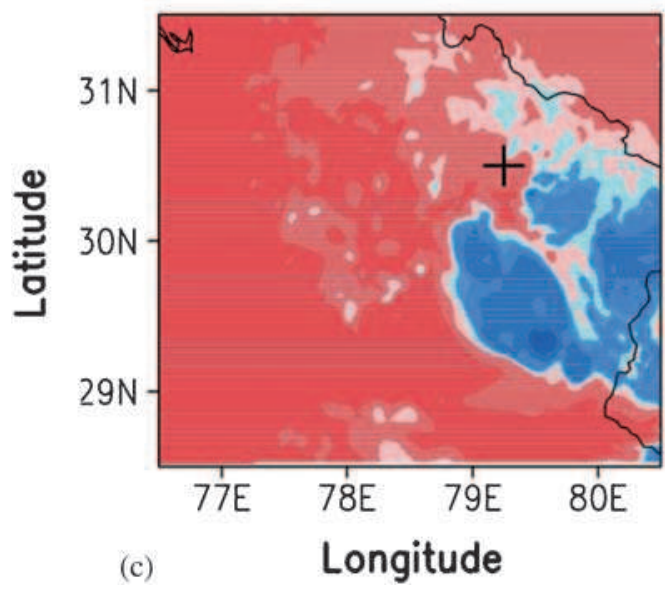

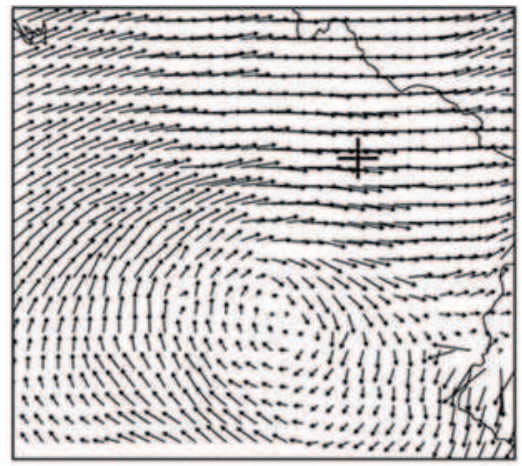

(b)

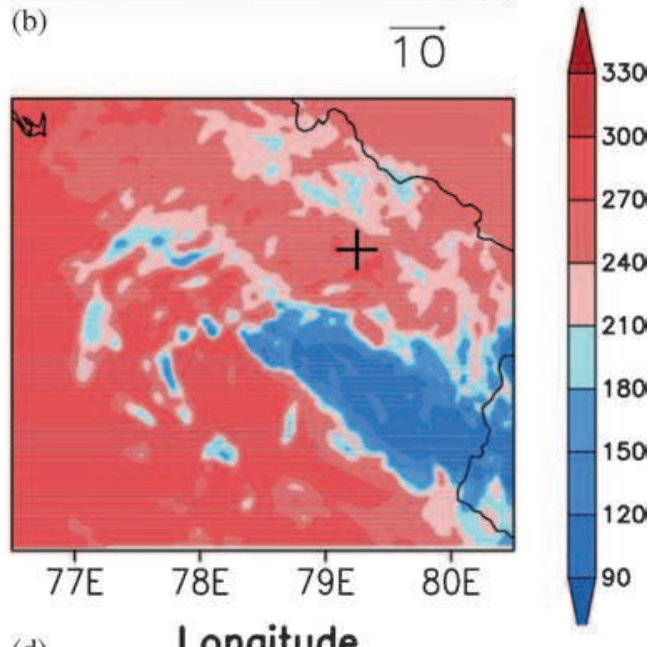
Longitude

Figure 6. Wind circulation ( $\mathrm{m} \mathrm{s}^{-1}$; vector) at $200 \mathrm{hPa}$ on 13 September 201218 UTC at $3 \mathrm{~km}$ grid spacing (a) with explicit physics and (b) with parameterized physics. Outgoing longwave radiation ( $\mathrm{W} \mathrm{m}^{-2}$; shaded) on 13 September $201218 \mathrm{UTC}$ at $3 \mathrm{~km}$ resolution (c) with explicit physics and (d) with parameterized physics. Plus sign indicates location of Ukhimath.
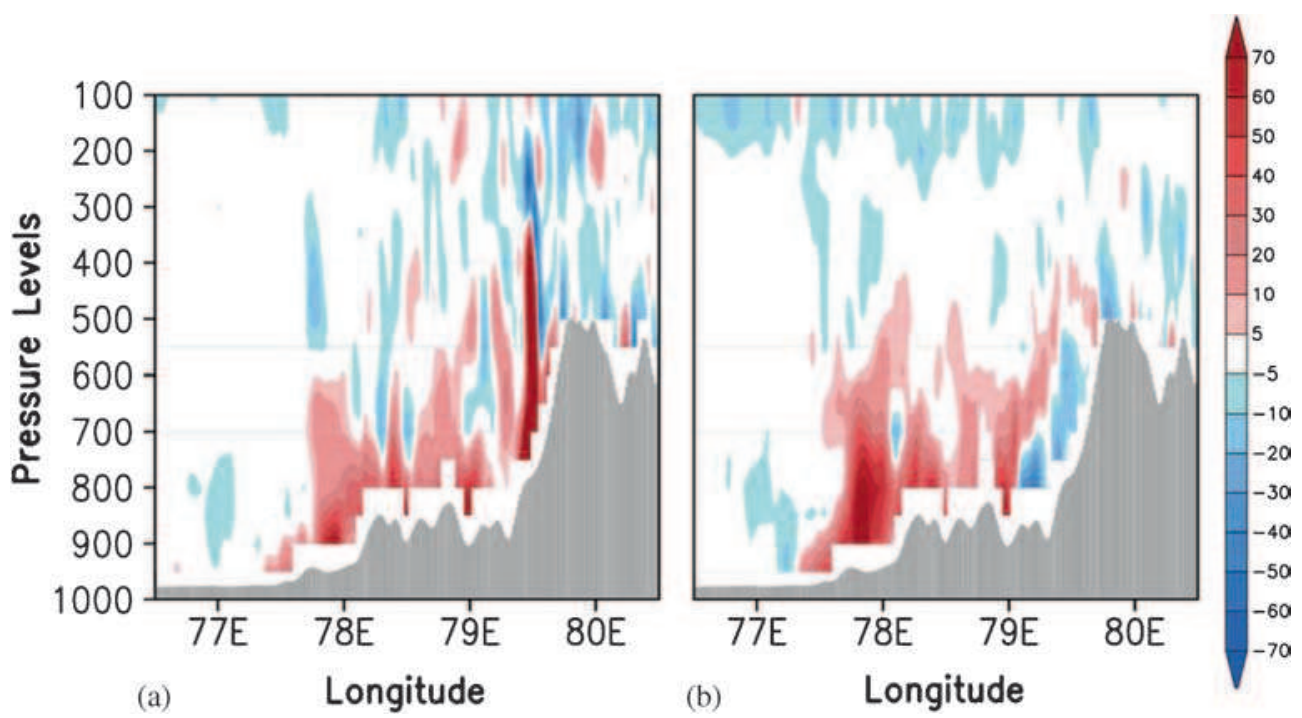

Figure 7. Longitude and height distribution of model simulated relative vorticity $\left(\times 10^{-5} \mathrm{~s}^{-1}\right)$ on 13 September 2012 18 UTC at $3 \mathrm{~km}$ model grid spacing at $30^{\circ} 19^{\prime} 49^{\prime \prime} \mathrm{N}$ with (a) explicit physics and (b) with parameterized physics. Topography is shown in grey.

corresponds to lower OLR conditions. When convection is explicitly treated in the model, a strong upper-level $200 \mathrm{hPa}$ divergence is visible, indicating a lower-level convergence corresponding to the intense precipitation event (figure 6a). The circulation intensifies begining from 13 September 2012 
12 UTC in the model with explicit physics (figure not depicted). Similarly, figure 6(c) depicts vigorous cloud formation as shown by reduced OLR on 13 September 201218 UTC around southeast of Ukhimath region when convection is explicitly considered. The strong anomalous divergence seen in the upper level with the corresponding convergence in the lower levels (discussed ahead) is emblematic of a strong vertical convective rising motion and aids the development of a convective system. This intense convection is also illustrated by the cloud cover conditions and a region of heavy precipitation. The rising wind over the steep relief of the Himalayas is largely responsible for the orographic rainfall. Further, the region of upper-level wind divergence and low OLR aligns with the region of precipitation maxima in the explicitly modelled simulation. Thus, the overall circulation pattern depicts that the model is able to explicitly simulate the corresponding circulation patterns leading to the convective event. When using parameterized physics in the model, a southwest displaced anticyclonic circulation is noted at 13 September 201218 UTC with no organized divergence field and the model did not resolve the convection required for the storm development as noted by the higher OLR values. This highlights the inability of the model to identify precipitation features when parameterizing convection.

Longitude and pressure distribution of vorticity in the $3 \mathrm{~km}$ grid spacing domain is shown in figure 7 , for the two different model simulations along $30^{\circ} 19^{\prime} 49^{\prime \prime} \mathrm{N}$. Strong positive and negative vorticity zones are seen over the region of maximum precipitation showing the vertical extent of the convective activity. The increasing positive vorticity tendency is indicative of the intensification of a cyclonic vertical circulation and the ensuing instability in the region. There is a zone of positive vorticity next to a region of the updraft core of the storm. This vorticity advection assists the wind flow along the Himalayan topography which sets a trigger for the event. In the explicit physics simulation, higher vorticity values are simulated than in the parameterized physics simulation $\left(50 \times 10^{-5} \mathrm{~s}^{-1}\right.$ higher) when considering the region of $79^{\circ} 28^{\prime} 09^{\prime \prime} \mathrm{E}$, where the intense precipitation occurred and was simulated. There is a step increase in vorticity along the steep terrain of the Himalayas over the valley region in explicit

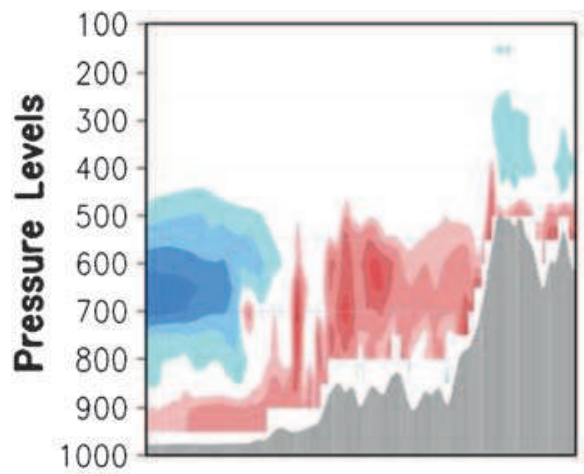

(a)

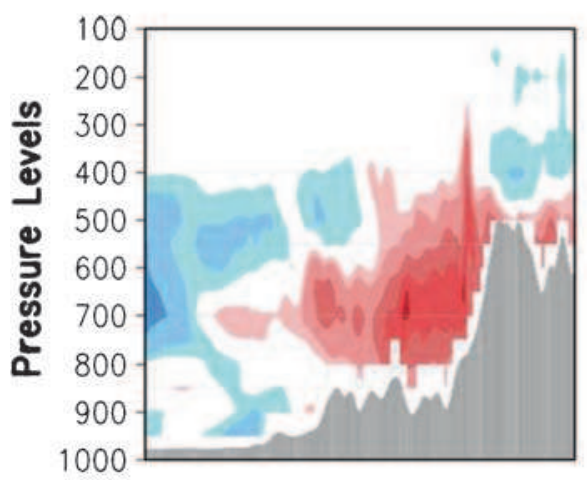

(c)

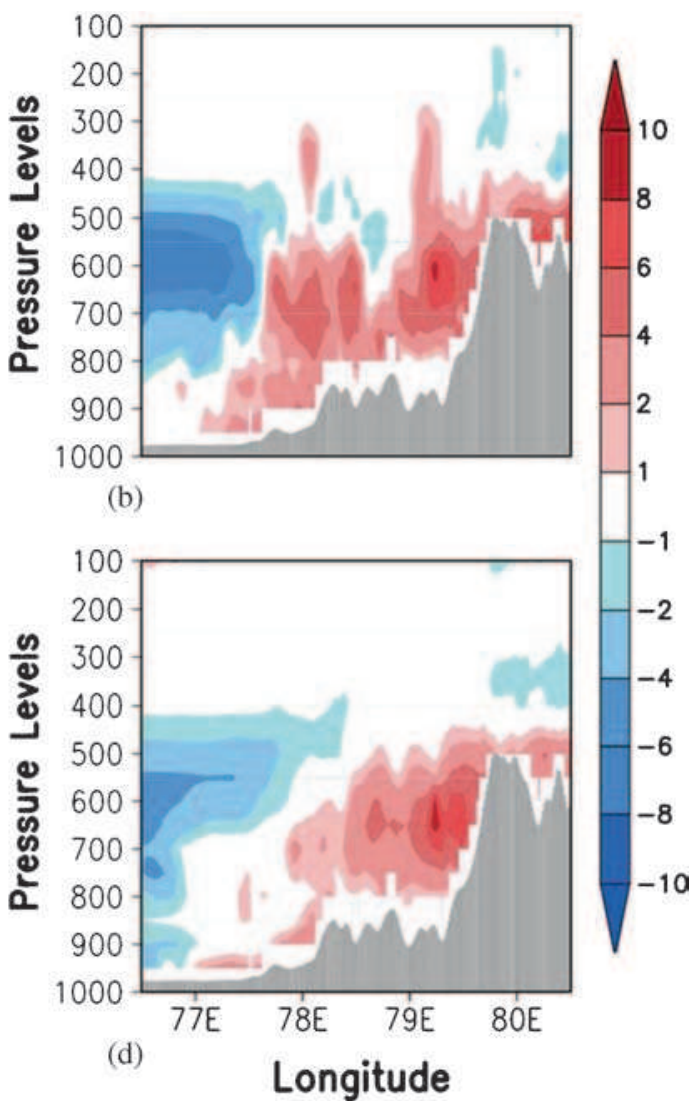

(d)

Figure 8. Longitude and height distribution of perturbation of equivalent potential temperature (EPT) for explicitly resolved model simulation at $3 \mathrm{~km}$ resolution (at $30^{\circ} 19^{\prime} 49^{\prime \prime} \mathrm{N}$ ) for (a) 13 September 201206 UTC, (b) 13 September 201212 UTC, (c) 13 September 201218 UTC, and (d) 14 September 201200 UTC. Topography is shown in grey. 
physics. This region demarcates a zone of stronger updrafts and convective activity along the steep landform leading to the heavy precipitation. Chen et al. (2007) study describes the similar impact of complex orography in Tibetan plateau on a frontal storm event.

\subsection{Analysis of model simulation with explicitly resolved convection}

From the above discussion, it is noted that the succesful simulation of the storm event requires a high spatial resolution that can permit explicit convection resolving scales. The atmospheric fields over this region with explicit physics simulation have been analyzed in detail in this section.

Figure 8 depicts the perturbation of equivalent potential temperature (EPT) along the region of intense precipitation. The EPT perturbation is calculated by subtracting the domain averaged EPT from each grid value. The regions of positive perturbations of EPT, represent the regions of higher temperature and moisture content and high instability. These regions of instability contribute to the thermodynamically induced storms (Tompkins 2001). The simulated fields shows a clear region of increasing instability developing over Ukhimath and surrounding areas from 13 September 201206 UTC. The EPT perturbation peaks at 13 September 201212 UTC and shows a drop at 14 September 2012 00 UTC, indicating the sharp increase of instability or potential energy, which is required for the convective cell development. Afterwards, there is fast decrease in the instability, reducing the perturbation in the EPT. Orographic precipitation shows increased EPT as described in Chiao et al. (2004). With a clear increase in the EPT along the slope of Himalayas, it can be concluded that orographic forcing influences this storm. Whereas, maximum convective available potential energy (CAPE) (at $30^{\circ} 19^{\prime} 49^{\prime \prime} \mathrm{N} ; 79^{\circ} 28^{\prime} 09^{\prime \prime} \mathrm{E}$ ), decreases from the peak value of $1192-618 \mathrm{~J} \mathrm{~kg}^{-1}$ between 13 September 201212 UTC and 14 September 201200 UTC, showing the release of instability and energy in the form of convective activity. Thus, convection also plays a major role along with the orography causing the storm.

Figure $9(\mathrm{a}-\mathrm{b})$ shows the vertical structure of $\mathrm{u}-\mathrm{w}$ wind along $30^{\circ} 19^{\prime} 49^{\prime \prime} \mathrm{N}$ and $\mathrm{v}-\mathrm{w}$ wind along

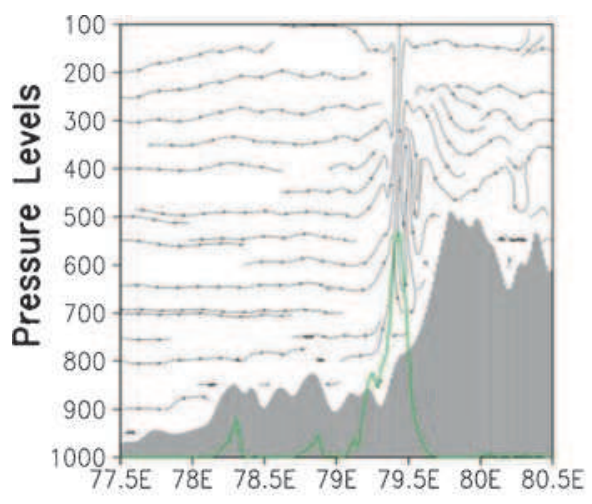

(a)

Longitude

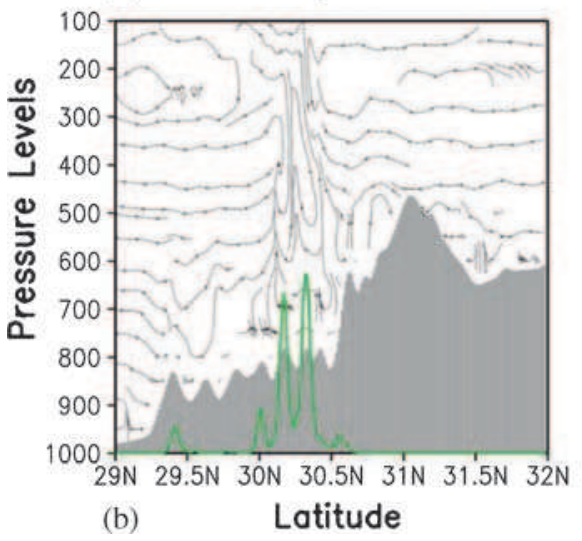

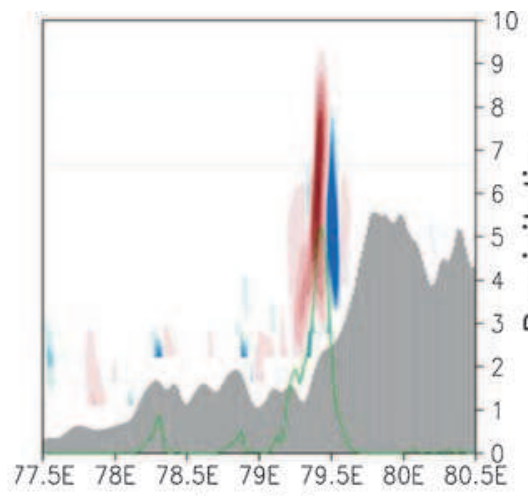

(c)

Longitude

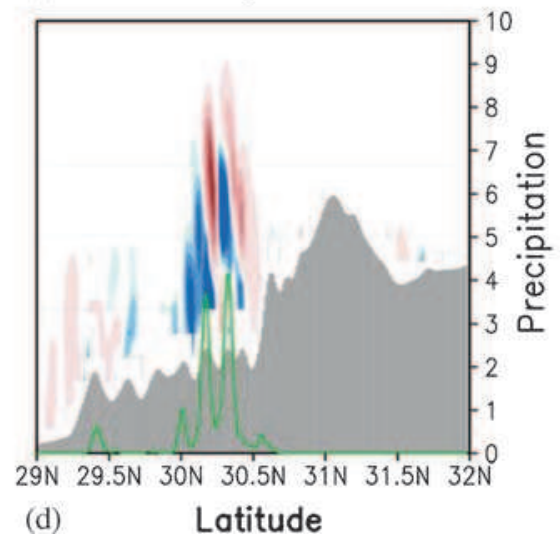

(d) Latitude

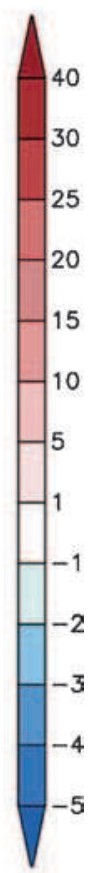

Figure 9. (a) Longitude and height distribution (arrows) of zonal and vertical wind along $30^{\circ} 19^{\prime} 49^{\prime \prime} \mathrm{N}$, (b) latitude and height distribution (arrows) of meridional and vertical wind along $79^{\circ} 28^{\prime} 09^{\prime \prime} \mathrm{E}$, (c) longitude and height distribution of vertical moisture flux $\left(\mathrm{m} \mathrm{s}^{-1}\right.$, shaded) along $30^{\circ} 19^{\prime} 49^{\prime \prime} \mathrm{N}$, and (d) latitude and height distribution vertical moisture flux $\left(\mathrm{m} \mathrm{s}^{-1}\right.$, shaded) along $79^{\circ} 28^{\prime} 09^{\prime \prime} \mathrm{E}$, with precipitation $(\mathrm{cm})$ shown in green line on the right-hand side vertical axis for 13 September 201218 UTC with explicit physics for horizontal grid spacing of $3 \mathrm{~km}$. Topography is shown in grey. 
$79^{\circ} 28^{\prime} 09^{\prime \prime}$ E respectively, together with the precipitation for the model simulation with explicit convection at 13 September 201218 UTC. This is the location of displaced maxima of reflectivity marked in figure 3(a). The large-scale flow below $400 \mathrm{hPa}$ is unobstructed until it encounters the topography. This flow curves along the relief of the Himalayas generating small vortices via orographic forcing. Also noted in figure 9(a), for above $700 \mathrm{hPa}$ there are anomalous circulation patterns. In this region, there is also a convergence from both sides leading to generation of vortices and a region of updraft zone being formed as the wind rises upwards. Around $200 \mathrm{hPa}$, the vertical wind diverges, as also noted in figure 6(a). There is a clear precipitation peak zone along the region of anomalous circulation. Similarly, in figure 9(b), the impact of orography on the large-scale wind flow is seen. There is anomalous divergence seen around $200 \mathrm{hPa}$ at $30^{\circ} 19^{\prime} 49^{\prime \prime} \mathrm{N}$ which coincides with the precipitation peak intensity. Figure $9(\mathrm{c}-\mathrm{d})$ shows the vertical moisture flux as a product of vertical wind and specific humidity. In figure 9(c), strong positive moisture flux is seen around $79^{\circ} 28^{\prime} 09^{\prime \prime} \mathrm{E}$, showing an upward movement of wind along with higher amounts of specific humidity in the region attributed to convection and orographic lifting. This coincides with the maximum precipitation intensity noted during the event. Similarly, high precipitation amounts are seen along $30^{\circ} 19^{\prime} 49^{\prime \prime} \mathrm{N}$ also, with stronger upward moisture flux corresponding to the convection that leads to the storm formation and culmination (figure 9d). In sumary, moisture incursion along the monsoonal trough leads to the wind flow towards the Himalayan mountain ranges. The buoyant moisture laden air rises under the influence of convection and orography. The zone updraft shown in the figures demarcates the storm cell formation due to the rising moist air.

Figure 10(a) shows the spatial distribution of model simulated reflectivity on 13 September 18 UTC for the simulation with explicit convection. Increased reflectivity values are attributed to the presence of hydrometeors in the atmosphere, indicating precipitation clouds. The model simulates reflectivity values up to $40 \mathrm{dBZ}$ over the high precipitation locale, which compares well with the observed DWR reflectivity in figure 1(b). There is, however, a small spatial displacement observed in the reflectivity values; therefore, for a detailed analysis of hydrometeor mixing ratios, the displaced location is considered (shown as a dotted cross). The vertical distribution of combined hydrometeor (cloudwater, cloud ice, rainwater, snow and graupel) mixing ratios and reflectivity are shown in figure $10(b-c)$ at the location of maximum reflectivity. The hydrometeors mixing ratios represent the cloud formation in the vertical and reflectivity

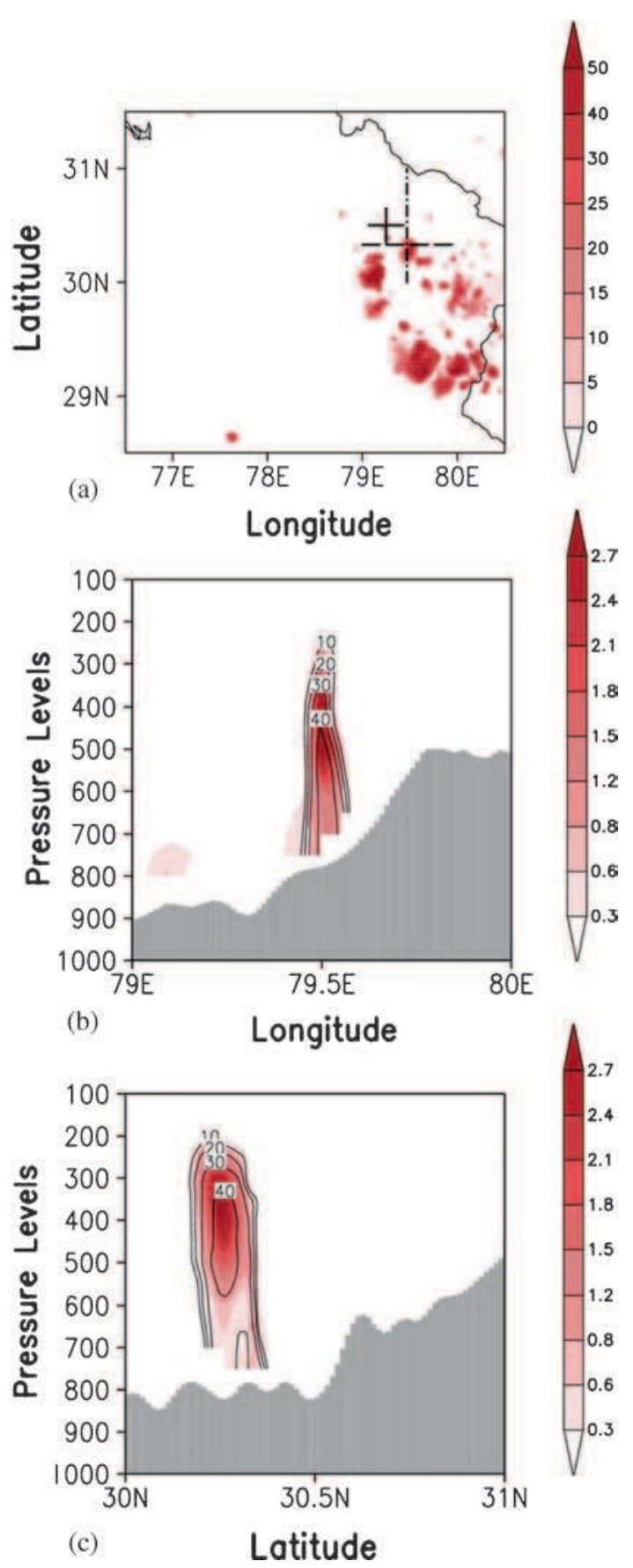

Figure 10. (a) Spatial distribution of model simulated maximum reflectivity (dBZ) with the plus sign depicting Ukhimath and the dotted cross sign showing the location of maxima for maximum reflectivity (at $30^{\circ} 19^{\prime} 49^{\prime \prime} \mathrm{N} ; 79^{\circ} 28^{\prime} 09^{\prime \prime} \mathrm{E}$ ), (b) longitude and height distribution (along $30^{\circ} 19^{\prime} 49^{\prime \prime} \mathrm{N}$ along the long dashed line from figure 11a) of reflectivity (dBZ; contour) and combined mixing ratio of hydrometeors $\left(\mathrm{kg} \mathrm{kg}^{-1}\right.$; shaded), and (c) latitude and height distribution (along $79^{\circ} 28^{\prime} 09^{\prime \prime} \mathrm{E}$ along the short dashed line from figure 11a) of reflectivity (dBZ; contour) and combined mixing ratio of hydrometeors $\left(\mathrm{kg} \mathrm{kg}^{-1}\right.$; shaded) for 13 September 201218 UTC at $3 \mathrm{~km}$ grid spacing with explicit physics. Combined mixing ratio of hydrometeors is the sum of mixing ratios of cloudwater, rainwater, cloudice, snow and graupel. 


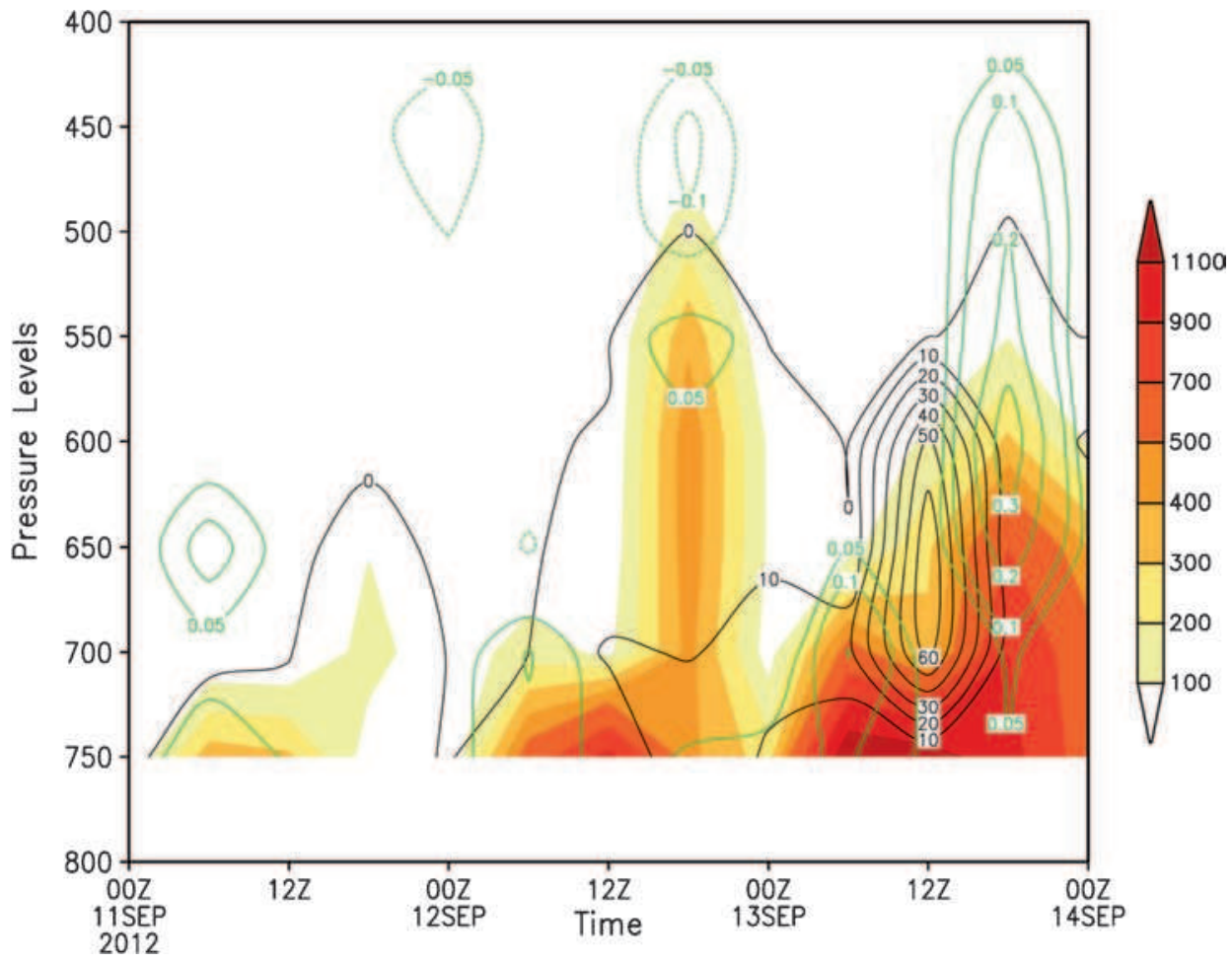

Figure 11. Temporal and height distribution of model simulated convective available potential energy, CAPE $\left(\mathrm{J}^{\mathrm{kg}}{ }^{-1}\right.$; shaded), convective inhibitive energy CIN ( $\mathrm{J} \mathrm{kg}^{-1}$; black contours) and specific humidity anomaly ( $\mathrm{g} \mathrm{kg}^{-1}$; green contours) with explicit physics for horizontal model resolution of $3 \mathrm{~km}$.

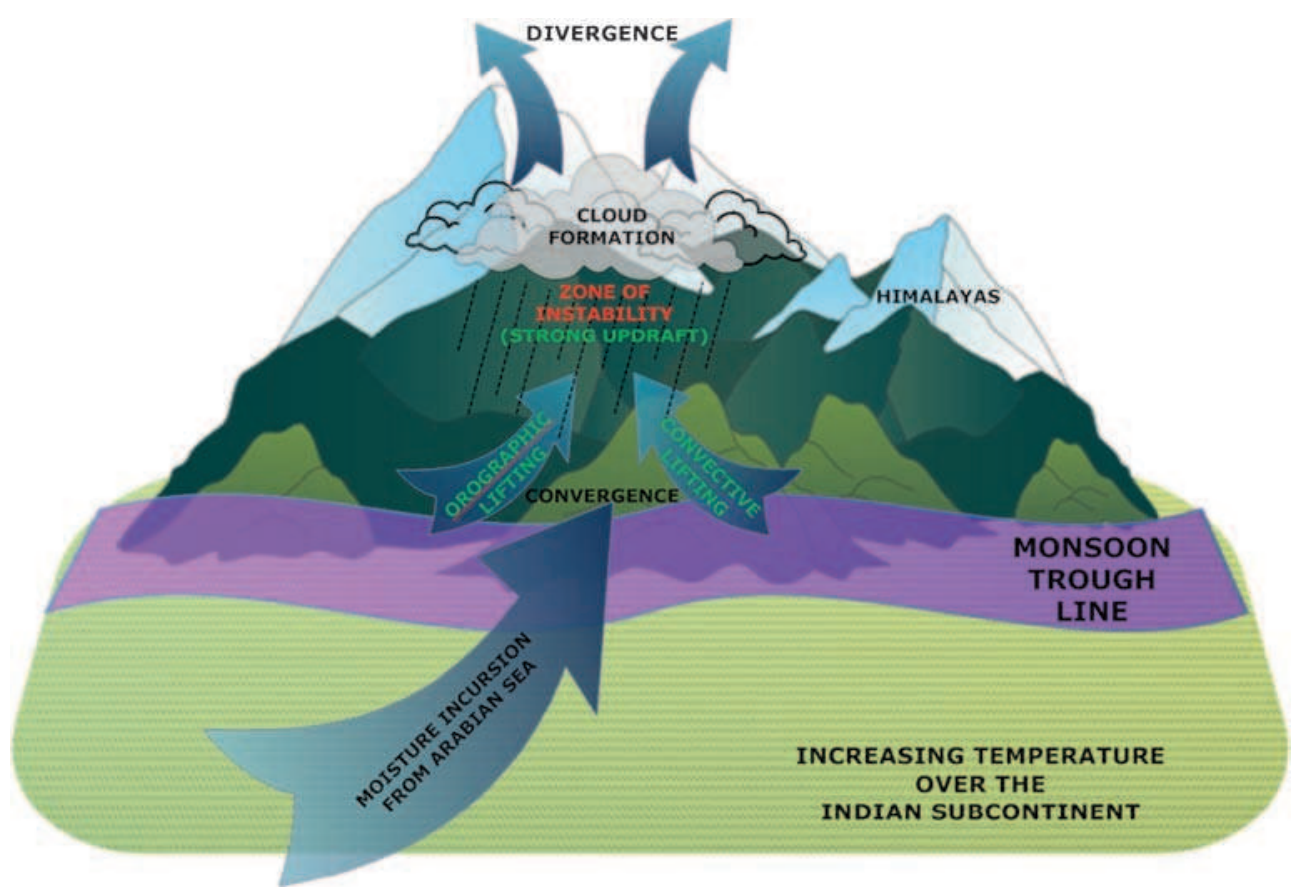

Figure 12. Conceptual illustration of the heavy precipitation event over Ukhimath.

represents the rain reflectivity. From the figures it can be concluded that the cloud formation reached up to $250 \mathrm{hPa}$.
The time series analysis of CAPE, convective inhibitive energy (CIN) and specific humidity anomaly along vertical axis at $30^{\circ} 19^{\prime} 49^{\prime \prime} \mathrm{N}$ and 
v-w wind along $79^{\circ} 28^{\prime} 09^{\prime \prime} \mathrm{E}$ is shown in figure 11 . Low level CAPE develops from 13 September 2012 00UTC onwards. This denotes the potential energy available in the atmosphere that can be converted to kinetic energy required for storm generation. But storm formation is not seen during this time period due to presence of inhibitive energy (CIN) which tries to resort stability to the environment. At 13 September 201218 UTC, there is high CAPE but low CIN which provides the kinetic energy for the updraft formation. The specific humidity anomaly shows high moisture content in the atmospheric column during the same time period. This moisture content is the source of the cloud formation or the hydrometeor particles.

\section{Conclusions}

A recent heavy precipitation event at Rudraprayag (Ukhimath) is the focus of this study. Study conclusions are summarized below.

\subsection{Should $3 \mathrm{~km}$ grid spacing consider convective parameterization or explicit convection?}

This event was simulated to understand the various dynamical characteristics associated with the intense precipitation event using the WRF model at triple nested domain resolution. The $3-\mathrm{km}$ grid spacing domain has been simulated with (1) explicit physics and with (2) parameterized physics for cumulus convection. The model-simulated precipitation clearly shows the occurrence of high intensity precipitation on the night of 13 September 2012 , as is also seen in the observation over Ukhimath with model simulation explicitly resolving convection. The explicit simulation underestimated the intensity of the precipitation peaks, but was able to represent the thermodynamical features associated with a convective system. The underestimation of precipitation intensity can be attributed partly to the reduced forcing from initial and boundary conditions in the large scale analysis due to sparse observational network (Mohanty and Dimri 2004).

The simulation with parameterized cumulus scheme could not properly simulate the different features associated with the convective precipitation event. Over this orographically complex region, high resolution (finer grid spacing) represents the orographic forcing with greater efficiency. As discussed above, most studies suggest use of hybrid physics in the ranges of $3-25 \mathrm{~km}$ resolution (Molinari and Dudek 1992). Our results show that that simulation with unparameterized or explicit convection at $3 \mathrm{~km}$ resolution is able to capture the convective instability and simulate cloud processes at grid scale level successfully, while significant errors occured with cumulus parameterization consideration. In the parameterized simulation of this study, excessive convective instability is suppressed, thus removing the driving force for storm formation. The Himalayan region is prone to strong localized convection due to orographic barriers, as in this weather event, the explicit physics was successful where the parameterized physics was not. With this study we provide additional support that convection should be simulated explicitly in mesoscale models at $3 \mathrm{~km}$ resolution over highly structured terrain, and the convection parameterization should not be included when explicit convection is considered. This can be attributed to the fact that sub-grid scale convection can be computed over a regime of variable orography. The results can also be considered as an example of the uncertainty that still exists in the convective parameterization scheme when applying over the Himalayan region.

\subsection{Impact of $W R F$ ver 3.4 .1 vs. ver 3.0}

According to Sun and Barros (2013), the boundary layer (YSU) scheme in the older version of the model produced reduced vertical mixing. In the upgraded versions, changes in the model do not cause the excessive mixing of boundary layer in the stable conditions (Sun and Barros 2013). The new model version specifically fixes the stable surface conditions improving forecasts at night time (discussed at www.mmm.ucar.edu/wrf/wrfv3.4.1/ updates-3.4.1.html). Hu et al. (2013) provide a detailed analysis, suggesting that an improved YSU scheme that reduces the near surface turbulent mixing in the planetary boundary layer during night time. Comparing the simulation with the two different model versions with explicit physics in this study, it is noted that WRF model (version 3.4.1) shows a stronger storm formation than with the version 3.0. The variables such as OLR, EPT, vorticity, CAPE and reflectivity show higher intensities with the newer version. With these changes the precipitation intensity shows more similar results to the observation data.

\subsection{Dynamic feedbacks associated with the precipitation event}

It can be concluded that this heavy precipitation event shows characteristic features represented by convective 'systems containing an intense convective echo' as described by Houze et al. (2007) and Medina et al. (2010). The convective 
system occurrence was recorded during the late monsoonal period in the Himalayan region. The convective system can be classified as containing a deep and intense convective echo as the reflectivity during the storm is around $40 \mathrm{dBZ}$. This convective weather system can also be classified as 'disorganized short-lived convection' as described in Barros et al. (2004), showing a duration of less than 6 hrs. During the initiation of the convective system, wind flow from the Arabian Sea provided the moisture to the large-scale synoptic flow, which when passing over the Thar Desert region increases its buoyancy due to sensible heat incursion. This event is considered a part of the monsoonal precipitation over Indian subcontinent as a well marked low pressure zone is observed along the monsoon trough zone. The southeasterly flow seen before the convective systems is impacted by the drier flow from the north leading to a region of moisture convergence over the Rudraprayag region. The moisture incursion provides the buoyancy to the air. Further, the available potential energy leads to release of instability when the flow reaches the foothills of the Himalayas. The release of convection and moisture incursion corresponds to the upward flow. This convective activity over the steep relief of the Himalayan terrain is important for the sudden burst of precipitation. Such orographically enhanced convective storms provide highly intense precipitation (Houze et al. 2007; Medina et al. 2010). Chiao et al. (2004) observed similar precipitation patterns over the Alps due to orographic lifting in a heavy rainfall event with deep convection.

A schematic for the storm formation is presented in figure 12. Monsoon trough zone over the region along with moisture incursion causes the development of convective activity and develops instability in the atmosphere, seen in the form of increasing CAPE. With the interaction of Himalayan topography, regions of positive vorticity and vertical wind movement support orographic lifting. The Himalayan topography aids mechanical lifting of the moist air to the zone of instability beyond the level of free convection. Increased reflectivity and EPT along with the unstable atmosphere, denotes the generation of a region of instability which leads to the maintenance of the unstable ascent via thermodynamic forcing which is enhanced via orographic forcing. Thus, the formation of updraft zone over the region is driven thermodynamically and enhanced due to the steep topography. The updraft is associated with convergence of air at lower levels and corresponding divergence at upper levels. Mesoscale convergence occurring along with convection enhances instability in the atmosphere leading to stronger convection (Chen and Orville 1980). The convergence with divergence aloft is observed at a localized level, which forms the updraft core of the storm. The incoming moisture from Arabian Sea advects along the topography and rises over the Himalayas such that the vertical column is inundated with water vapour. This orographically induced convection causes the hydrometeor concentrations to reach upper and mid-tropospheric levels and contribute to heavy cloud formation. Also the rate of condensation and formation of cloud water droplets is increased due to faster ascent of moisture laden air (Roe 2005). All these factors lead to heavy precipitation on the windward side of the mountain.

This storm event was also associated with a landslide disaster. Not all heavy precipitation events lead to landslides or flashflood, but regions such as the Rudraprayag region, can experience such related disasters due to the surface geomorphology and surface runoff caused by heavy precipitation events. Such disasters become more common when combined with other factors like the changes in landuse patterns. As noted above, DMMC (2012) reported that the region around Ukhimath is frequented by storms leading to high amounts of precipitation around the monsoon season, and is also impacted by flashfloods and landslides accompanied by such a scenario. Study of this heavy precipitation event has provided additional substantiation to the idea of Himalayan topography along with the monsoonal circulation being the trigger to such events (Dimri and Niyogi 2013; Dimri et al. 2015). Improvements in numerical weather prediction can be made by better representation of landcover and landuse, topographical information and data assimilation into the models (Mohanty and Dimri 2004). The studies will help in the development of early warning systems as a method of mitigation of damage that might be caused by such disasters.

\section{Acknowledgements}

Study benefitted in part through CSIR fellowship to AC and NSF grant AGS-0847472 (A. Bamzai) to DN. The TRMM data used in this study were acquired using the GES-DISC Interactive Online Visualization and Analysis Infrastructure (Giovanni) as part of the NASA's Goddard Earth Sciences (GES) Data and Information Services Center (DISC). Satellite data included in the study is from Meteosat-5, operated by the European Organisation for the Exploitation of Meteorological Satellites (EUMETSAT). FNL analyses used as initial and boundary conditions in this study is published by NCEP 
and Computational Information Systems Laboratory (CISL), US. Thanks to Kristen Rasmussen (University of Washington) for providing satellite images with brightness temperature. Thanks also to Tracey Saxby, Integration and Application Network, University of Maryland Centre for Environmental Science (http://ian.umces.edu/ imagelibrary/displayimage-6256.html) for illustration of mountains used in the conceptual diagram. Authors would like to thank Ms D Stanley for the English editing of the manuscript.

\section{References}

AMS 2005 Meteorology glossary; http://glossary.ametsoc. org/wiki/Cloudburst.

Arakawa A 2004 The cumulus parameterization problem: Past, present, and future; J. Climate 17 2493-2525.

Ashrit R 2010 A report on investigating the Leh cloudburst; http://www.ncmrwf.gov.in/ncmrwf/Cloudburst_Investigation_ Report.pdf.

Barros A P, Kim G, Williams E and Nesbitt S W 2004 Probing orographic controls in the Himalayas during the monsoon using satellite imagery; Nat. Hazards Earth Syst. Sci. 4 29-51.

Barros A P, Chiao S, Lang T J, Burbank D and Putkonen J 2006 From weather to climate - Seasonal and interannual variability of storms and implications for erosion processes in the Himalaya; Geol. Soc. Am. Spec. Paper 398.

Chen C H and Orville H D 1980 Effects of mesoscale convergence on cloud convection; J. Appl. Meteorol. 19 256-274.

Chen J, Li C and He G 2007 A diagnostic analysis of the impact of complex terrain in the eastern Tibetan Plateau, China, on a severe storm; Arctic, Antarctic and Alpine Research 39 699-707.

Chiao S, Lin Y L and Kaplan M L 2004 Numerical study of orographic forcing of heavy precipitation during MAP IOP-2B; Mon. Wea. Rev. 132 2184-2203.

Das S, Ashrit R and Moncrieff M W 2006 Simulation of a Himalayan cloudburst event; J. Earth Syst. Sci. 115 299-313, doi: 10.1007/BF02702044.

Deng A and Stauffer D R 2006 On improving 4-km mesoscale model simulations; J. Appl. Meteorol. Clim. 45 361-381.

Dimri A P and Niyogi D 2013 Regional climate model application at subgrid scale on Indian winter monsoon over the western Himalayas; Int. J. Climatol. 33 2185-2205, doi: $10.1002 /$ joc.3584.

Dimri A P, Niyogi D, Barros A P, Ridley J, Mohanty U C, Yasunari T and Sikka D R 2015 Western disturbances: A review; Rev. Geophys., doi: 10.1002/2014RG000460.

DMMC 2012 Investigation in the areas around Okhimath in Rudraprayag district on the aftermath of landslide incidences of Sept. 2012 - A report, http://dmmc.uk.gov.in/ files/pdf/Okhimath_Report_Final.pdf.

Done J, Davis C A and Weisman M 2004 The next generation of NWP: Explicit forecasts of convection using the Weather Research and Forecasting (WRF) model; Atmos. Sci. Lett. 5 110-117.

Economic Times 2012 Uttarakhand cloudburst toll climbs to 42, Published Sept. 17, 2012; http://articleseconomictimes indiatimescom/2012-09-17/news/33902753_1_cloudburst-uk himath-and-srinagar-uttarakhand.
Gomes J L and Chou S C 2010 Dependence of partitioning of model implicit and explicit precipitation on horizontal resolution; Meteorol. Atmos. Phys. 106 1-18.

Hobley D E J, Sinclair H D and Mudd S M 2012 Reconstruction of the major storm event from its geomorphic signature: The Ladhak floods, 6 August 2010; Geology 40 48-486, doi: 10.1130/G32935.1.

Hong S Y and Lim J O J 2006 The WRF single-moment 6class microphysics scheme (WSM6); J. Atmos. Sci. 42(2) $129-151$.

Hong S Y, Noh Y and Dudhia J 2006 A new vertical diffusion package with an explicit treatment of entrainment processes; Mon. Wea. Rev. 134 2318-2341.

Houze R A Jr, Wilton D C and Smull B F 2007 Monsoon convection in the Himalayan region as seen by the TRMM precipitation radar; Quart. J. Roy. Meteorol. Soc. 133 1389-1411, doi: 10.1002/qj.106.

Hu X M, Klein P M and Xue M 2013 Evaluation of the updated YSU planetary boundary layer scheme within WRF for wind resource and air quality assessment; J. Geophy. Res. Atmos. 118 490-505, doi: 10.1002/ jgrd.50823.

Huffman G J 1997 Estimates of root-mean-square random error contained in finite sets of estimated precipitation; J. Appl. Meteorol. 36 1191-1201.

Huffman G J, Adler R F, Bolvin D T, Nelkin G G E J, Bowman K P, Hong Y, Stocker E F and Wolff D B 2007 The TRMM multi-satellite precipitation analysis: Quasi-global, multi-year, combined-sensor precipitation estimates at fine scale; J. Hydrometeor. 8 38-55.

IMD 2010 Cloudburst over Leh (Jammu and Kashmir); http://imd.gov.in/doc/cloud-burst-over-leh.pdf.

IMD 20122012 Southwest monsoon, end of season report; http://www.imd.gov.in/section/nhac/dynamic/endofseasonreport.pdf.

Kain J S 2004 The Kain-Fritsch convective parameterization: An update; J. Appl. Meteorol. 43 170-181.

Kumar A, Dudhia J, Rotunno R, Niyogi D and Mohanty U C 2008 Analysis of the 26 July 2005 heavy rain event over Mumbai, India using the Weather Research and Forecasting (WRF) model; Quart. J. Roy. Meteorol. Soc. 134 1897-1910, doi: 10.1002/qj.325.

Kumar M S, Shekhar M S, RamaKrishna S S V S, Bhutiyani M R and Ganju A 2012 Numerical simulation of cloud burst event on August 5, 2010, over Leh using WRF mesoscale model; Nat. Hazards 62 1261-1271, doi: 10.1007/s11069-012-0145-1.

Kumar A, Houze R A Jr, Rasmussen K L and Peters-Lidard C 2014 Simulation of flash flooding storm at the steep edge of the Himalayas; J. Hydrometeorol. 15 212-228, doi: http://dx.doi.org/10.1175/JHM-D-12-0155.1.

Leung L R and Ghan S J 1995 A subgrid parameterization of orographic precipitation; Theor. Appl. Climatol. 52 95118.

Medina S, Houze R A Jr, Kumar A and Niyogi D 2010 Summer monsoon convection in the Himalayan region: Terrain and land cover effects; Quart. J. Roy. Meteorol. Soc. 136 593-616, doi: 10.1002/qj.601.

Mohanty U C and Dimri A P 2004 Location-specific prediction of the probability of occurrence and quantity of precipitation over the western Himalayas; Wea. Forecasting 19 520-533.

Molinari J and Dudek M 1992 Parameterization of convective precipitation in mesoscale numerical models: A critical review; Mon. Wea. Rev 120 326344 .

Prasad S Kiran, Mohanty U C, Routray A, Osuri Krishna K, Ramakrishna S S V S and Niyogi D 2014 Impact of Doppler weather radar data on thunderstorm simulation 
during STORM pilot phase - 2009; Nat. Hazards $\mathbf{7 4}$ 1403-1427.

Rasmussen K L and Houze R A Jr 2012 A flash flooding storm at the steep edge of high terrain: Disaster in the Himalayas; Bull. Am. Meteor. Soc. 93 1713-1724, doi: 10.1175/BAMS-D-11-00236.1.

Roe G H 2005 Orographic precipitation; Ann. Rev. Earth Planet. Sci. 33 645-671, doi: 10.1146/annurev.earth.33.092203.122541.

Romatschke U and Houze R A Jr 2010 Extreme summer convection in South America; J. Climate 23 3761-3791, doi: http://dx.doi.org/10.1175/2010JCLI3465.1.

Romatschke U and Houze R A Jr 2011 Characteristics of precipitating convective systems in the south Asian monsoon; J. Hydrometeorol. 12 3-26, doi: 10.1175/ 2010JHM1289.1.

Skamarock W C 2004 Evaluating mesoscale NWP models using kinetic energy spectra; Mon. Wea. Rev. 132 30193032 .

Skamarock W C, Klemp J B, Dudhia J, Gill D O, Barker D M, Duda M G, Huang X, Wang W and Powers G J 2008 A description of the advanced research WRF Version 3; http://www.mmm.ucar.edu/wrf/users/docs/ arw_v3.pdf.

Sphere India 2012 Situation report - Rudraprayag cloudburst 16th September 2012; http://reliefweb.int/sites/relie
fweb.int/files/resources/Situation\%2520report\%2520-\%252 02\%2520_Rudraprayag\%2520cloudburst_ \%5B1\%5D.pdf.

Sun X and Barros A P 2013 High resolution simulation of tropical storm Ivan (2004) in the southern Appalachians: Role of planetary boundary-layer schemes and cumulus parameterization; Quart. J. Roy. Meteorol. Soc., doi: $10.1002 /$ qj2255.

Thayyen R J, Dimri A P, Kumar P and Agnihotri G 2013 Study of cloudburst and flashfloods around Leh, India during August 4-6, 2010; Nat. Hazards 65 175-2204, doi: 10.1007/s11069-012-0464-2.

Tompkins A M 2001 Organization of tropical convection in low vertical wind shears: The role of cold pools; J. Atmos. Sci. 58 1650-1672.

Wang W, Barker D M, Bruyère C, Duda M G, Dudhia J, Gill D O, Michalakes J and Rizvi S 2010 WRF Version 3 Modeling System User's Guide; http://www.mmm.ucar.edu/wrf/users/docs/user_ guide_V3.0/ARWUsersGuideV3.pdf.

Weisman M L, Skamarock W C and Klemp J B 1997 The resolution dependence of explicitly modeled convective systems; Mon. Wea. Rev. 125 527-548.

Wooley R R 1946 Cloudburst floods in Utah 1850-1938; United States Department of the Interior, Geological Survey, Water-supply paper 994. 